\title{
Silagem de cana-de-açúcar comparada a fontes tradicionais de volumosos suplementares no desempenho de vacas de alta produção ${ }^{1}$
}

\section{Oscar Cezar Muller Queiroz², Luiz Gustavo Nussio³, Patrick Schmidt², José Leonardo Ribeiro², Mateus Castilho Santos ${ }^{2}$, Maity Zopollatto ${ }^{2}$}

\author{
1 Pesquisa financiada pela FAPESP. \\ 2 Programa de Pós-graduação em Ciência Animal e Pastagens, USP/ESALQ. \\ ${ }^{3}$ Departamento de Zootecnia, USP/ESALQ.
}

RESUMO - O experimento foi conduzido com o objetivo de avaliar o desempenho de animais de alta produção alimentados com rações com diferentes fontes de volumosos. Foram availados os seguintes tratamentos: cana-de-açúcar in natura (CA); silagem de cana-de-açúcar inoculada com L. buchneri (SCA); silagem de milho (SM); e mistura de cana-de-açúcar in natura e silagem de milho (CASM). O experimento foi conduzido em quadrado latino $4 \times 4$ com períodos de 21 dias, de modo que, nos sete últimos dias, realizou-se a coleta de amostras. Além da avaliação de desempenho, foram feitas análises bromatológicas dos volumosos, das rações e das sobras e análises da composição do leite e da estabilidade aeróbia dos volumosos e das rações. Observaram-se diferenças quanto ao consumo de MS, que foi maior quando os animais foram alimentados com a SCA (23,5 kg/ dia) e a CASM (23,5 kg/dia). Todas as rações propiciaram aos animais elevada produção leiteira (24,4 a 25,5 kg/dia), que não diferiu entre os volumosos. A composição do leite variou somente quanto ao teor de gordura, que foi maior quando os animais foram alimentados com SM $(36,1 \%)$ e CASM $(34,8 \%)$. Os resultados de estabilidade aeróbia comprovaram efeito positivo da aditivação bacteriana na SCA, que apresentou a maior estabilidade entre os volumosos (13,63 horas). A ração contendo SM como fonte de volumoso apresentou a menor estabilidade, o que provavelmente explica o baixo consumo dos animais nesse tratamento. A SCA é uma alternativa tecnicamente viável à utilização da planta in natura e ambas podem proporcionar elevadas produções de leite, desde que as rações sejam corretamente balanceadas. A inoculação com $L$. buchneri melhorou o valor nutritivo e reduziu as perdas fermentativas.

Palavras-chave: consumo, estabilidade aeróbia, L. buchneri, silagem de milho

\section{Sugar cane silage as compared to traditional supplemental sources of forage in the performance of high production cows}

\begin{abstract}
The experiment was carried out to evaluate the performance of high produce animals fed rations with different sources of forage, what resulted in the treatment: fresh sugarcane (SC), sugarcane silage inoculated with L. buchneri (SCS), corn silage (CS) and mixture of fresh sugarcane and corn silage (SCCS). The experiment was carried out in a $4 \times 4$ latin square design with periods of 21 days, and the last 7 days, of each period was used for sample collections. Besides the performance evaluation, chemical analyses of forages, rations and orts were performed and analyses of milk composition and aerobic stability of forages and rations were also made. There was differences for DM intake, which was higher for SCS (23.5 kg/day) and SCSM (23.5 kg/day). All rations provided to the animals high milk production (24.4-25.5 kg/day), which did not differ among the animals. The milk composition varied only as for fat content, which was higher in the animals fed CS (36.1\%) and in the SCCS (34.8\%). The aerobic stability results showed positive effect of the bacterial aditivation in SCS, which presented the highest aerobic stability among the forages (13.63 hours). The ration with CS as source of forage presented the wors stability, which could explain the lower intake by the animals in this treatment. The SCS is a technical viable alternative to the use of fresh plant and both can proportionate high milk production, as long as, the rations are properly balanced. The inoculation with $L$. buchneri showed capable to bring benefits for nutritional value and fermentative losses.
\end{abstract}

Key Words: aerobic stability, consumption, corn silage, L. buchneri

\section{Introdução}

O cultivo de cana-de-açúcar caracteriza-se como uma das mais importantes atividades do agronegócio brasileiro.
O Brasil se destaca como maior produtor mundial de canade-açúcar, com produção de 423 milhões de toneladas na última safra (2004-2005). Contudo, a planta não éimportante somente para o setor industrial do açúcar e do álcool, uma 
vez que relatos de 1913 já mencionavam seu uso como fonte de volumoso suplementar aos animais.

Tradicionalmente, a cana-de-açúcar é colhida, picada e fornecida aos animais diariamente. Entretanto, o uso da planta em sistemas de produção intensivo e de grande escala tem aumentado e, conseqüentemente, houve aumento da demanda por novas tecnologias. Segundo Junqueira (2006), um dos principais fatores que norteiam as decisões pelo uso da cana-de-açúcar é o problema logístico decorrente da colheita diária da forragem, mais intenso em propriedades com grandes rebanhos.

A utilização da cana-de-açúcar na forma de silagem tem sido uma alternativa para contornar os problemas do corte diário, além da praticidade no uso em todo o sistema de produção. Por sua grande quantidade de carboidratos solúveis, a cana-de-açúcar é altamente susceptível à ação de leveduras. No ambiente anaeróbio do silo, as leveduras são capazes de gerar perdas significativas de matéria seca em razão da fermentação alcoólica. Segundo Nussio et al. (2005), o acúmulo de etanol pode não somente representar perdas do material ensilado, mas também perdas decorrentes da recusa dos animais.

No cenário que envolve o uso da cana-de-açúcar ensilada, o meio científico tem pesquisado inúmeros aditivos capazes de controlar a população de leveduras e propiciar a redução das perdas decorrentes dos processos fermentativos. Neste sentido, Pedroso (2003) observou melhora na dinâmica fermentativa de silagens de cana-deaçúcar inoculadas com L. buchneri, o que foi ratificado pelos menores teores de etanol e perdas totais. Junqueira (2006), ao avaliar animais alimentados com silagens de cana-de-açúcar tratadas com aditivos químicos e bacterianos, verificou que o tratamento com uréia (1\%) proporcionou melhores resultados.

Este trabalho foi realizado com o objetivo de comparar a composição do leite e o desempenho de animais de alta produção alimentados com silagem de cana-de-açúcar ou fontes tradicionais de volumosos, como a cana-de-açúcar in natura e a silagem de milho.

\section{Material e Métodos}

O experimento foi realizado no Departamento de Zootecnia, setor ruminantes, na USP/ESALQ, em Piracicaba, SP. A silagem de milho foi produzida sem aditivos e acondicionada em silo tipo trincheira, enquanto a silagem de cana-de-açúcar foi armazenada em silo tipo poço e enriquecida com aditivo bacteriano, produto Lalsilcana ${ }^{\circledR}$ Lasil, constituído de cepa Lactobacillus buchneri 40788 (5×10 4 ufc/g forragem fresca). Ambas as silagens foram utilizadas somente após 60 dias de fermentação.

Os tratamentos foram constituídos das diferentes rações, balanceadas de modo a serem isoprotéicas e isoenergéticas (Tabela 1), para igual potencial de produção nos diferentes tratamentos. Constituiu-se como fonte de variação apenas o efeito causado pelo volumoso.

As 48 vacas holandesas utilizadas nesse experimento foram alocadas em quatro baias de um confinamento do tipo free stall. O período experimental foi de 84 dias, divididos em quatro períodos de 21 dias, representados por 14 dias de adaptação e sete de coleta. O consumo foi ad libitum e calculado de forma a permitir sobra de $10 \%$. O fornecimento das rações foi realizado durante os períodos de ordenha (6h e 18h). A cana-de-açúcar da área de capineira foi colhida em dias intercalados e picada diariamente no momento do fornecimento.

Durante a semana de coleta, amostras da ração fornecida, das sobras e dos volumosos foram coletadas diariamente. As amostras de leite foram coletadas três vezes durante a semana em dias alternados. Juntamente com as amostras de leite, foram monitoradas as produções individuais dos animais.

No segundo período de avaliação, amostras dos volumosos e das rações foram coletadas para realização de um

Tabela 1 - Composição em ingredientes das rações (\%MS)

\begin{tabular}{lcccc}
\hline Ingrediente & Cana-de-açúcar & Silagem de cana-de-açúcar & Silagem de milho & Cana-de-açúcar + Silagem de milho (50:50) \\
\hline Cana & 40,0 & - & - & 22,51 \\
Silagem cana & - & 40,0 & - & - \\
Silagem de milho & - & - & 50,0 & 22,51 \\
Milho moído fino & 7,99 & 7,99 & - & - \\
Polpa cítrica & 12,9 & 12,9 & 14,8 & 17,52 \\
Caroço de algodão & 10 & 10 & 10 & 10 \\
Farelo de algodão & 12 & 12 & 12,1 & 10 \\
Farelo de soja & 14,0 & 0,70 & 0,70 & 14,39 \\
Bicarbonato de sódio & 0,70 & 2,38 & 2,38 & 0,70 \\
Mineral & 2,38 & & 2,38
\end{tabular}

${ }_{1}$ In natura. 
ensaio de estabilidade aeróbia. O delineamento experimental utilizado foi o quadrado latino $4 \times 4$ e os dados foram analisados com o procedimento GLM do programa estatístico SAS (1999). As médias foram comparadas utilizando-se o recurso LSMEANS, com nível de significância de 5\%. Os animais foram alocados nos tratamentos, considerando o número de parições, a produção de leite, medida durante o período pré-experimental, e os dias em lactação visando manter a homogeneidade dentro de cada quadrado.

As amostras compostas das rações fornecidas, das sobras e dos volumosos foram secas em estufa de ventilação forçada, a $60^{\circ} \mathrm{C}$ durante 72 horas (Silva, 1981). Na seqüência, foram moídas em peneira com orifícios de $1 \mathrm{~mm}$ e analisadas quanto aos teores de proteína bruta (PB), cinzas, fibra em detergente ácido (FDA), fibra em detergente neutro (FDN), extrato etéreo (EE) e matéria seca (MS). As amostras úmidas coletadas durante os últimos sete dias de cada período foram prensadas para obtenção do extrato (Kung Jr., 1996), que foi utilizado para as análises de etanol, carboidratos solúveis (Dubois, 1956) e ácido lático (Pryce, 1969).

O desempenho dos animais foi mensurado durante a semana de coleta de dados de cada período. O consumo foi obtido subtraindo as sobras da quantidade de MS fornecida. A mensuração da quantidade de MS fornecida e da sobra foi realizada todos os dias e amostras para determinação do teor de MS foram coletadas durante toda a semana.

A produção de leite foi obtida individualmente por meio de medidores de produção acoplados ao sistema de ordenha. As medições foram feitas três vezes na semana, em dias intercalados e nos dois horários de ordenha. Para determinação da composição do leite, foram analisados os teores de proteína, gordura, lactose, sólidos totais e sólidos não-gordurosos.

O desempenho animal foi caracterizado pela produção diária de leite ( $\mathrm{kg} / \mathrm{dia})$, pela produção corrigida para 4\% de gordura ( $\mathrm{kg} / \mathrm{dia}$ ) e pela eficiência de produção em função da produção corrigida para 4\% de gordura (kg/kg) (NRC-Dairy cattle, 2001).

Amostras de $4 \mathrm{~kg}$ das rações e dos volumosos foram usadas no ensaio de estabilidade aeróbia. As silagens de cana e de milho, a cana in natura, a mistura de silagem de milho + cana-de-açúcar in natura e suas respectivas rações foram contempladas com três repetições, totalizando oito tratamentos e 24 unidades experimentais.

O ensaio de estabilidade aeróbia foi realizado em uma sala equipada com sistema de controle de temperatura que permite variação de meio grau em relação à temperatura média, que foi de $24^{\circ} \mathrm{C}$ durante o ensaio.
As amostras (4 kg) foram acomodadas em baldes plásticos abertos, sem compactação da massa. Um sensor de temperatura data-logger instalado no centro geométrico de cada balde foi calibrado para aferir a temperatura a cada 2 horas. A estabilidade aeróbia foi avaliada considerando o tempo necessário para se atingir a variação de $2^{\circ} \mathrm{C}$ das silagens em relação à temperatura ambiente (expressa em hora) (Kung, 2000). Ainda para determinação da estabilidade, foram calculados o acúmulo de temperatura durante os cinco primeiros dias e durante todo o período (dez dias) (ADITE-5 e ADITE-10), a diferença média diária entre a temperatura das silagens expostas ao ar e a temperatura ambiente (expressa em ${ }^{\circ} \mathrm{C}$ ), o tempo para elevação da temperatura (em horas), a temperatura máxima (expressa em ${ }^{\circ} \mathrm{C}$ ) e o tempo para se atingir a temperatura máxima (em horas).

O delineamento experimental utilizado foi o inteiramente casualizado e os dados foram analisados pelo procedimento GLM do programa estatístico SAS (1999). As médias foram comparadas utilizando-se o recurso LSMEANS, a 5\% de significância. Os 24 baldes contendo as amostras foram alocados de maneira aleatória dentro da sala de estabilidade aeróbia.

\section{Resultados e Discussão}

A silagem de cana-de-açúcar apresentou maior período de estabilidade aeróbia (13,25 horas) em comparação aos outros volumosos (Tabela 2), cuja média foi de apenas 3,16 horas. De modo geral, as rações apresentaram maior estabilidade aeróbia em relação aos volumosos avaliados exclusivamente, com exceção daquela contendo silagem de milho, cujos valores de estabilidade aeróbia foram iguais aos da silagem. O aumento da estabilidade da silagem de cana-de-açúcar inoculada com L. buchneri corrobora os resultados obtidos por Pedroso (2003), Siqueira et al. (2004) e Toledo Filho et al. (2004).

Toledo Filho et al. (2004) observaram valores de estabilidade aeróbia de 14,4 horas em silagem de cana aditivada com L. buchneri ( $5 \times 10^{4} \mathrm{ufc} / \mathrm{g}$ forragem fresca). Quando comparados volumosos exclusivos e rações, esses autores verificaram que, de modo geral, as rações contendo ingredientes concentrados apresentaram maior estabilidade aeróbia (55 horas e 8 minutos) em comparação aos volumosos exclusivos (19,2 horas).

A adição desses ingredientes à silagem com L. buchneri elevou a estabilidade aeróbia de 14,4 horas para um total de 96 horas. De acordo Toledo Filho et al. (2004), os ingredientes concentrados alteram o teor de MS do meio, podendo aumentar a pressão osmótica, o que inibiria o desenvolvi- 
mento de microrganismos aeróbios e, conseqüentemente, diminuiria seus efeitos deletérios.

O tempo para elevação da temperatura foi baixo em todos os volumosos (Tabela 2). O volumoso que mais demorou a aquecer foi aquele contendo cana in natura + silagem de milho: 2,4 horas para detecção de uma variação progressiva de $0,1^{\circ} \mathrm{C}$. Os valores obtidos diferem consideravelmente daqueles reportados na literatura. Junqueira (2006), avaliando silagens de cana-de-açúcar com diferentes aditivos, observou aumento na temperatura das silagens inoculadas com L. buchneri ( $5 \times 10^{4}$ ufc/g forragem fresca) somente após 132 horas de exposição ao ar, o que pode ser explicado pela menor precisão dos sensores de temperatura utilizados, os quais foram representados por termômetros convencionais. Os sensores de temperatura utilizados neste experimento (data-loggers) podem registrar variações de de $0,1^{\circ} \mathrm{C}$, ou seja, são dez vezes mais sensíveis que os termômetros freqüentemente utilizados.

A menor temperatura máxima foi obtida na silagem de cana-de-açúcar $\left(42,15^{\circ} \mathrm{C}\right)$, seguida pela cana-de-açúcar in natura $\left(44,43^{\circ} \mathrm{C}\right)$. Contudo, este comportamento não foi observado quando esses volumosos foram avaliados juntamente com os ingredientes concentrados. Apesar de a ração contendo silagem de milho ter apresentado a maior temperatura $\left(50,93^{\circ} \mathrm{C}\right)$, o tempo necessário para atingir esse valor foi um dos maiores (133,3 horas), o que revela lenta utilização da energia.

As rações contendo cana-de-açúcar e silagem de milho também resultaram em lenta utilização da energia até o pico máximo de temperatura, de 153,6 e 127,5 horas, respectivamente. O tempo para atingir a temperatura máxima nos volumosos foi menor (58,5 horas) que nas rações (109,6 horas), com exceção da silagem de milho (Tabela 2). Os valores para temperatura máxima foram próximos aos observados por Junqueira (2006), que observou $41,75^{\circ} \mathrm{C}$ como a temperatura máxima da silagem de cana-de-açúcar inoculada com L. buchneri. No entanto, esse valor foi atingido após 102 horas de estabilidade aeróbia.

O maior tempo para atingir a temperatura máxima, considerando que se tratava do mesmo tipo de material (silagem de cana-de-açúcar inoculada com L. buchneri), está associado à menor disponibilidade de carboidratos solúveis para o uso das populações pioneiras de microrganismos aeróbios.

O teor de carboidratos solúveis observado neste estudo foi maior (Tabela 3) que aquele verificado por Junqueira (2006), de 6,2\% na silagem após a abertura do silo (Tabela 3). Outro possível fator de redução na velocidade de utilização dos carboidratos é o teor de ácido acético produzido pelas bactérias, embora seja um parâmetro dificilmente mensurado e/ou abordado na literatura nacional.

Toledo Filho et al. (2004) também observaram aumento do tempo para se atingir a temperatura máxima quando compararam medidas obtidas em volumosos exclusivos com volumosos acrescidos de ingredientes concentrados. Esses autores reportaram variações de 45,6\% no aumento do tempo necessário para se atingir a temperatura máxima quando os ingredientes concentrados foram adicionados aos volumosos. Neste estudo, essa diferença foi de $46,8 \%$ (Tabela 2). A influência dos ingredientes sobre a pressão osmótica pode ser um dos fatores que ocasionam redução no desenvolvimento da população de microrganismos aeróbios, resultando nas diferenças observadas.

O tempo para atingir a temperatura máxima não diferiu entre a silagem de milho e a ração contendo este volumoso (Tabela 2), o que provavelmente está relacionado à nãoimportância dos carboidratos solúveis como fonte de energia, até mesmo no volumoso exclusivo. O teor de carboidratos solúveis remanescente na silagem de milho é ínfimo (Tabela 3). O aquecimento da massa depende, portanto, do perfil de ácidos orgânicos e da concentração de carboidratos.

Tabela 2 - Avaliação da estabilidade aeróbia das diferentes fontes de volumosos e suas respectivas rações

\begin{tabular}{|c|c|c|c|c|c|c|c|c|c|}
\hline \multirow[b]{2}{*}{ Parâmetro } & \multicolumn{4}{|c|}{ Volumoso } & \multicolumn{4}{|c|}{ Dieta } & \multirow[t]{2}{*}{ EPM } \\
\hline & CA & SCA & SM & CASM & CA & SCA & SM & CASM & \\
\hline EA (h) & $4,33 c$ & $13,25 b$ & $1,58 \mathrm{c}$ & $3,58 c$ & $11,37 b$ & $23,83 a$ & $3,00 \mathrm{c}$ & $15,66 \mathrm{~b}$ & 1,49 \\
\hline TIE (h) & $1,33 \mathrm{c}$ & $0,87 \mathrm{c}$ & $1,50 \mathrm{bc}$ & $2,41 \mathrm{a}$ & 1,62abc & $1,16 \mathrm{c}$ & $1,00 \mathrm{c}$ & $2,16 a b$ & 0,27 \\
\hline TMáx $\left({ }^{\circ} \mathrm{C}\right)$ & $44,43 c$ & $42,15 d$ & $48,56 b$ & $48,43 b$ & $47,65 b$ & $46,70 \mathrm{~b}$ & $50,93 a$ & $46,80 \mathrm{~b}$ & 0,68 \\
\hline TTmáx (h) & $33,91 \mathrm{~d}$ & $43,50 \mathrm{~d}$ & $127,58 a b$ & $29,25 d$ & $153,62 \mathrm{a}$ & $94,83 \mathrm{bc}$ & 133,33ab & $56,83 \mathrm{~cd}$ & 14,81 \\
\hline ADITE-5 & $77,91 \mathrm{~cd}$ & $60,37 \mathrm{e}$ & $88,20 a$ & $84,67 \mathrm{ab}$ & $81,09 \mathrm{bc}$ & $77,53 \mathrm{~cd}$ & $53,11 \mathrm{f}$ & $74,52 d$ & 1,50 \\
\hline ADITE-10 & $131,03 d$ & $115,42 \mathrm{e}$ & $158,99 b$ & $143,41 \mathrm{c}$ & $170,76 a$ & $158,13 b$ & $148,08 \mathrm{c}$ & $163,71 \mathrm{ab}$ & 2,56 \\
\hline
\end{tabular}

CA = cana-de-açúcar, SCA = silagem de cana-de-açúcar, $\mathrm{SM}=$ silagem de milho, CASM = cana-de-açúcar + silagem de milho, 50:50.

Médias dos quadrados mínimos com letras diferentes na mesma linha diferem $(P<0,05)$.

EA = estabilidade aeróbia, TIE = tempo para elevação da temperatura, TMáx = temperatura máxima, TTmáx = tempo necessário para se atingir a temperatura máxima, ADITE-5 e ADITE-10 = acúmulo da diferença média diária entre a temperatura das silagens expostas ao ar e a temperatura ambiente em 5 e 10 dias. 
Tabela 3 - Composição nutricional das silagens de cana-deaçúcar inoculadas com aditivos químicos, bacterianos e associações de aditivos(\%MS)

\begin{tabular}{|c|c|c|c|c|c|c|}
\hline \multirow[t]{2}{*}{ Item } & \multicolumn{6}{|c|}{ Forragem oferecida } \\
\hline & CA & SCA & SM & CASM & DP & Amplitude \\
\hline MS (\%) & 32,19 & 31,65 & 29,93 & 28,72 & 1,59 & 3,47 \\
\hline MM & 1,68 & 3,15 & 4,17 & 2,91 & 1,02 & 1,47 \\
\hline PB & 2,79 & 3,25 & 8,15 & 5,41 & 2,45 & 5,36 \\
\hline FDN & 52,38 & 53,48 & 51,13 & 53,78 & 1,20 & 2,65 \\
\hline FDA & 30,31 & 30,52 & 29,91 & 32,35 & 1,08 & 2,44 \\
\hline $\mathrm{EE}$ & 0,70 & 1,12 & 2,42 & 1,56 & 0,73 & 1,72 \\
\hline Etanol & ND & 0,45 & ND & ND & ND & ND \\
\hline Ác. lático & $0 \quad \mathrm{ND}$ & 3,08 & 4,21 & 2,57 & 0,84 & 1,64 \\
\hline $\mathrm{pH}$ & 6,8 & 3,59 & 3,85 & 4,05 & 0,32 & 0,73 \\
\hline \multirow[t]{2}{*}{$\mathrm{CT}$} & 25,71 & 16,10 & 2,59 & 20,35 & 9,87 & 23,12 \\
\hline & \multicolumn{6}{|c|}{ Ração experimental - Oferecida } \\
\hline MS (\%) & 48,15 & 48,29 & 45,11 & 45,00 & 1,83 & 3,29 \\
\hline MM & 4,45 & 4,93 & 7,29 & 5,71 & 1,24 & 2,84 \\
\hline $\mathrm{PB}$ & 15,01 & 13,96 & 16,09 & 15,86 & 0,97 & 2,13 \\
\hline FDN & 38,63 & 41,81 & 39,63 & 39,89 & 1,33 & 3,18 \\
\hline FDA & 23,91 & 27,73 & 25,45 & 27,07 & 1,72 & 3,82 \\
\hline $\mathrm{EE}$ & 3,37 & 3,80 & 4,38 & 3,60 & 0,43 & 1,01 \\
\hline \multirow[t]{2}{*}{$\mathrm{pH}$} & 6,78 & 4,89 & 4,64 & 4,71 & 1,02 & 2,14 \\
\hline & \multicolumn{6}{|c|}{ Ração experimental - Sobras } \\
\hline MS (\%) & 45,24 & 44,33 & 41,90 & 43,93 & 1,41 & 3,34 \\
\hline MM & 4,96 & 5,56 & 6,08 & 5,54 & 0,46 & 1,12 \\
\hline PB & 9,55 & 8,56 & 11,24 & 10,28 & 1,13 & 2,68 \\
\hline FDN & 50,27 & 49,51 & 47,29 & 50,98 & 1,60 & 3,69 \\
\hline FDA & 31,82 & 31,62 & 32,29 & 33,31 & 0,75 & 1,69 \\
\hline $\mathrm{EE}$ & 4,40 & 4,29 & 2,24 & 3,82 & 1,00 & 2,16 \\
\hline $\mathrm{pH}$ & 5,19 & 4,75 & 5,07 & 5,39 & 0,27 & 0,64 \\
\hline
\end{tabular}

$\mathrm{CT}=$ carboidrato total; $\mathrm{CA}$ = cana-de-açúcar, $\mathrm{SCA}=$ silagem de cana-deaçúcar, SM = silagem de milho, CASM = cana-de-açúcar + silagem de milho, 50:50.

A presença de carboidratos não solúveis ou um possível efeito dos ingredientes concentrados sobre o desenvolvimento microbiano reflete em valores de temperatura máxima mais tardios, o que poderia ser justificado pela alta correlação entre as variáveis envolvendo temperatura máxima e o ADITE-10, de 62,8\% para a temperatura máxima e 59,9\% para o tempo para atingir a temperatura máxima.

É possível observar que os maiores valores de ADITE-10 (Tabela 2) estejam relacionados aos tratamentos com valores de temperatura máxima mais elevados. Essa hipótese corrobora a definição de ADITE-10, ou seja, é maior o acúmulo da diferença média entre a temperatura ambiente e a temperatura das silagens nos dez dias de avaliação quando se tem o aumento tardio dessa variação, caso contrário, o ADITE-5 seria favorecido em termos numéricos. Os valores médios para ADITE-5 e ADITE- 10 foram 74,68 e 148,69 $\mathrm{C}$, respectivamente. Ambos os ADITES foram menores para a silagem de cana-de-açúcar, tanto na forma exclusiva como na ração $\left(60,37\right.$ e $\left.115,42^{\circ} \mathrm{C}\right)$. Os dados obtidos confirmam os resultados freqüentemente encontrados na literatura.
Junqueira (2006) obteve valores médios de ADITE-5 e ADITE-10 em torno de 43,6 e $151,5^{\circ} \mathrm{C}$, respectivamente, e, para silagem de cana-de-açúcar tratada com L. buchneri, 83,50 e $201,25^{\circ} \mathrm{C}$, respectivamente.

Valores menores de ADITE-5 em silagens de cana-deaçúcar inoculadas com $L$. buchneri são encontrados na literatura. Pedroso (2003) observou valores de $25^{\circ} \mathrm{C}$, enquanto Siqueira et al. (2004) observaram valores de $14,2^{\circ} \mathrm{C}$. O menor ADITE associado às silagens inoculadas com L . buchneri é decorrente da presença do ácido acético, que inibe o desenvolvimento microbiano durante o período de exposição da silagem ao ar. A não-metabolização dos carboidratos pelos microrganismos implica em menores variações de temperatura e, conseqüentemente, em menores acúmulos de temperatura.

Mesmo que as plantas tenham sido colhidas em diferentes épocas, a cana-de-açúcar in natura não diferiu significativamente da silagem de cana-de-açúcar para os parâmetros avaliados, com exceção da composição em cinzas, que foi maior para o volumoso na forma de silagem (Tabela 3). As diferenças no teor de carboidratos das duas fontes foram conseqüência da utilização de carboidratos solúveis pelos microrganismos epifíticos no material ensilado, ressaltando-se que o uso de aditivos microbianos pode, inclusive, acentuar esse consumo, como observado por Driehuis et al. (2001).

Os valores obtidos para os parâmetros avaliados estão de acordo com a literatura. Alcântara et al.(1989), trabalhando com tratamentos à base de cana-de-açúcar in natura e silagem de cana-de-açúcar controle, sem aditivos, obtiveram valores similares de MS, PB e cinzas entre os tratamentos; além disso, observaram que o teor de cinzas foi numericamente maior no volumoso ensilado.

As diferenças entre os teores de carboidratos também são freqüentemente reportadas na literatura. Pedroso (2003) obteve valores de $15,1 \%$ de carboidratos solúveis para silagens de cana-de-açúcar tratadas com L. buchneri.

O teor de 3,08\% de ácido lático (\% MS) verificado na silagem de cana-de-açúcar confirma a variação do ácido encontrada por Kung Jr. \& Stanley (1982). Contudo, esses autores verificaram que silagens produzidas com plantas em idade de rebrotação entre 12 e 15 meses apresentavam teores de ácido lático de 5,65 a 4,33\%. Portanto, a menor concentração deste ácido (Tabela 3) pode ser justificada pelo consumo de ácido lático pelo $L$. buchneri inoculado a silagem.

O teor de etanol verificado na silagem de cana-deaçúcar foi similar aos valores obtidos por Pedroso (2003) e Junqueira (2006), que, em condições similares, observaram 0,29 e 0,83\% na MS, respectivamente. Neste estudo, a 
avaliação químico-bromatológica da silagem de milho confirmou valores freqüentemente encontrados na literatura, como os descritos por Rosa et al. (2004), Abreu et al. (2004) e Roth et al. (2004).

Rosa et al. (2004), avaliando silagens de diferentes híbridos de milho, observaram participação de FDN e FDA de 55,76 e 28,92\%, respectivamente. Os autores reportaram valores similares de MS (30,69\%) e cinzas (3,61\%). Os valores de proteína encontrados na literatura variam de 9,74 (Rosa et al., 2004) a 5,25\% (Oliveira et al., 2003). Os valores de ácido lático observados neste estudo (Tabela 3) confirmam os freqüentemente encontrados na literatura internacional. Ranjit \& Kung Jr. (2000) obtiveram teor de ácido lático de 7,78\% MS em silagens de milho controle, enquanto Nishiro et al. (2003) obtiveram 6,41\% na MS.

Os resultados observados para o volumoso constituído de cana-de-açúcar in natura e silagem de milho foram próximos ou similares aos observados nesses dois volumosos individualmente.

As variações nos parâmetros químicos das rações são resultado do acréscimo dos ingredientes concentrados. O aumento significativo de MS em todas as rações é um fator importante, pois pode justificar seu lento aquecimento em relação aos volumosos (Toledo Filho et al., 2004). O material recusado pelo animal foi caracterizado nas amostras como um alimento mais fibroso, contendo maiores teores de FDN e FDA em todos os tratamentos. O maior teor de MS não foi somente resultado do acréscimo de ingredientes concentrados, mas também das partes vegetais normalmente deixadas pelos animais (caules e sabugos) e que continham menor teor de umidade.

As maiores partículas encontradas nas silagens de milho e recusadas pelos animais foram formadas pelo sabugo do milho. De acordo com Nussio et al. (2001), essa fração pode representar $13,6 \%$ da planta inteira e tem aproximadamente $52,3 \%$ de digestibilidade. No caso de silagem de cana ou cana-de-açúcar in natura, o material recusado normalmente é constituído de grandes partículas de colmo.

O consumo (Tabela 4) foi maior entre os animais alimentados com as rações contendo silagem de cana e cana-deaçúcar in natura + silagem de milho. O consumo de ração à base de cana-de-açúcar in natura foi intermediário e o da ração com silagem de milho, o menor. Apesar da variação no consumo, esse valor foi superior ao de $21,4 \mathrm{~kg}$ predito pelo NRC gado de leite (2001).

As produções comprovaram não existir diferenças entre os tratamentos, mesmo quando a produção foi corrigida para 4\% de gordura (Tabela 4). Em poucos trabalhos, são avaliados animais para alto desempenho alimentados com cana-de-açúcar in natura ou na forma ensilada.
Tabela 4 - Composição do leite e desempenho de animais alimentados com rações com diferentes fontes de volumoso

\begin{tabular}{lrrrr}
\hline Item & CA & SCA & SM & CASM \\
\hline Consumo de MS, kg/dia & $22,3 \mathrm{~b}$ & $23,5 \mathrm{a}$ & $21,3 \mathrm{c}$ & $23,5 \mathrm{a}$ \\
Produção de leite, kg/dia & 24,6 & 24,4 & 25,5 & 25,2 \\
PCG 4\%, kg/dia & 22,1 & 22,1 & 24,0 & 23,0 \\
Eficiência, kg/kg MS & $0,99 \mathrm{~b}$ & $0,95 \mathrm{~b}$ & $1,13 \mathrm{a}$ & $0,99 \mathrm{~b}$ \\
Gordura, g/kg & $33,4 \mathrm{~b}$ & $33,8 \mathrm{~b}$ & $36,1 \mathrm{a}$ & $34,8 \mathrm{ab}$ \\
Proteína, g/kg & 32,4 & 31,7 & 31,7 & 32,2 \\
Sólidos totais, g/kg & 116 & 116 & 118 & 118 \\
Lactose, g/kg & 42,7 & 42,6 & 42,4 & 42,6 \\
Sólidos não-gordurosos, g/kg & 83,3 & 82,5 & 82,4 & 83,0
\end{tabular}

CA = cana-de-açúcar, SCA = silagem de cana-de-açúcar, SM = silagem de milho, CASM = cana-de-açúcar + silagem de milho, 50:50.

Médias dos quadrados mínimos com letras diferentes na mesma linha diferem $(P<0,05)$.

Mendonça et al. (2004) avaliaram o desempenho de vacas holandesas alimentadas com rações à base de cana-deaçúcar in natura e observaram que o consumo de $15,8 \mathrm{~kg}$ de uma ração com $50 \%$ do volumoso resultou em produções de leite diárias de 20,1 kg.

Os resultados de consumo obtidos com as rações contendo silagem de milho como fonte de volumoso exclusivo ou parcial não estão totalmente de acordo com os reportados em outros trabalhos com cana-de-açúcar (Corrêa et al., 2003; Pires et al., 1999; Magalhães et al., 2004). Magalhães et al. (2004) avaliaram o desempenho de vacas holandesas e mestiças alimentadas com dietas contendo cana-de-açúcar in natura em substituição à silagem de milho e verificaram redução linear na produção com o aumento da participação da cana-de-açúcar na dieta. De acordo com esses autores, a substituição em 0; 33,33 e $100 \%$ por cana-de-açúcar ocasionou reduções de 24,17 ; 23,28 e 20,36 kg/dia na produção de leite, além de redução no consumo de MS de 20,03, 19,07 e 17,26 kg/dia, respectivamente.

Costa et al. (2005) avaliaram o desempenho produtivo de vacas leiteiras alimentadas com diferentes proporções de cana-de-açúcar e concentrado ou silagem de milho e observaram redução no consumo de alimento e na produção de leite com mesma participação percentual das silagens na ração. Contudo, essas diferenças não foram observadas com decréscimo de $20 \%$ na participação de cana-de-açúcar em relação à silagem de milho. $\mathrm{O}$ consumo pelos animais e a produção de leite quando fornecida a ração contendo $60 \%$ de silagem de milho foram 19,32 e 20,81 kg/dia, respectivamente, enquanto, quando alimentados com rações contendo $40 \%$ de cana-de-açúcar in natura, foram obtidos valores de 19,81 e 19,78 kg/dia.

Os valores encontrados neste estudo foram próximos aos observados por Costa et al. (2005), uma vez que não houve diferenças entre a produção dos animais alimentados 
com as silagens de milho ou cana-de-açúcar in natura (Tabela 4). Existe uma diferença percentual da participação de volumosos nas diferentes rações, pois a cana-deaçúcar in natura colabora com $40 \%$ do total de MS, enquanto a silagem de milho participa com $50 \%$ da MS total (Tabela 3).

Observa-se que o teor de gordura no leite e sua produção diferiram entre os tratamentos (Tabela 4). Entretanto, as produções de leite corrigidas para 4\% eliminaram essa diferença. Costa et al. (2005) não observaram diferenças na produção de leite corrigida entre os animais alimentados com rações contendo $60 \%$ de silagem de milho e aqueles alimentados com as rações contendo $40 \%$ de cana-deaçúcar in natura.

Os resultados de eficiência (Tabela 4) foram maiores para os animais alimentados com dietas contendo 50 ou $100 \%$ de silagem de milho como fonte de volumoso. Essa eficiência é resultado da relação entre produção de leite corrigida e consumo de MS. Assim, não só a produção de leite como também o teor de gordura são fatores diretamente relacionados a esse parâmetro. Quando alimentados com dietas contendo silagem de milho, os animais apresentaram produções de leite numericamente maiores, além de maior teor de gordura no leite, o que justifica os maiores valores de eficiência obtidos com essas rações.

A síntese de gordura no leite pode ser alterada pela concentração de ácido acético decorrente da fermentação de fibras ou de carboidratos não-estruturais. Os maiores teores de gordura no leite produzido por animais alimentados com as rações contendo milho (Tabela 4) possivelmente foram ocasionados pelo fato de a fibra de silagem de milho apresentar maior digestibilidade em comparação à fibra da cana-de-açúcar.

Existem na literatura diversos trabalhos avaliando a digestibilidade da porção fibrosa da planta de milho, da silagem de milho, da cana-de-açúcar in natura ou ensilada. Freqüentemente, esses trabalhos reportam a baixa digestibilidade da porção da cana-de-açúcar em comparação à planta de milho, que apresenta digestibilidade da FDN superior a 57\%. Antoniali et al. (2003) avaliaram cultivares de milho para silagem e reportaram valores de digestibilidade da FDN de 20 híbridos de milho que variaram entre 57,36 e 60,65\%. Lucci et al. (2003) observaram valores de digestibilidade de FDN para cana-deaçúcar in natura e silagem de cana-de-açúcar de 37,5\% e $43,1 \%$ da MS, respectivamente.

Outros fatores interferem na fermentação da fibra e, conseqüentemente, na síntese de gordura. Por exemplo, Pires et al. (1999), avaliando substituições de silagem de milho por cana-de-açúcar in natura, verificaram menores teores de gordura e menor eficiência quando o único volumoso fornecido aos animais foi silagem de milho. Com a substituição de $50 \%$ da silagem de milho por cana-deaçúcar, os autores verificaram aumento no pH ruminal, o que atribuíram à melhoria do ambiente ruminal, à melhor fermentação e ao aumento de 8,6\% nos teores de ácido acético no rúmen.

Os teores de proteína, sólidos totais, lactose e sólidos não-gordurosos (Tabela 4) variaram em pequena amplitude e resultaram em similaridade entre os dados obtidos com as diferentes rações. Os valores obtidos estão de acordo com dados de composição de leite encontrados na literatura.

Pires (1999), trabalhando com rações à base de silagem de milho e cana-de-açúcar in natura, observou teores de gordura de 2,98 e 3,59\% e teores de proteína de 2,94 e 3,06\%, respectivamente. Costa et al. (2005) observaram teores de $3,61 \%$ de gordura no leite em animais alimentados com rações à base de silagem de milho e 3,45\% para animais alimentados com rações com cana-de-açúcar. Os teores de proteína para os mesmos tratamentos foram de 3,65 e 3,63\%, respectivamente.

Segundo Frandson et al. (2003), a composição do leite pode ser alterada pela ração, de modo que os teores de gordura no leite aumentam quando fornecida ração com maiores níveis de energia. A concentração de proteína pode ainda ser minimamente modificada pelo aumento da concentração de proteína na ração. De acordo com esses autores, os outros componentes do leite sofrem variações menos sensíveis em relação ao teor de gordura ou proteína.

\section{Conclusões}

Rações contendo silagem de cana-de-açúcar ou a planta in natura atendem às exigências nutricionais de animais leiteiros de alta produção. O uso do aditivo bacteriano permite aumento da estabilidade aeróbia da silagem.

\section{Literatura Citada}

ABReU, A.G.; EVANGELiSTA, A.R.; AMARAL, P.N.C. et al. Avaliação do padrão de fermentação em silagens de milho ("Zea mays"L.). In: REUNIÃO ANUAL DA SOCIEDADE BRASILEIRA DE ZOOTECNIA, 41., 2004, Campo Grande. Anais... Campo Grande: Embrapa Gado de Corte, 2004. (CD-ROM).

ALCÂNTARA, E.; AGUILERA, A.; ELLIOT, R. et al. Fermentation and utilization by lambs of sugarcane harvested fresh and ensiled with and without $\mathrm{NaOH}$. 4. Ruminal kinetics. Animal Feed Science and Technology, v.23, p.323-331, 1989.

ANTONIALI, M.; REIS, R.A.; NUSSIO, L.G. et al. Avaliação de cultivares de milho (Zea mays.L) para a produção de silagem: 
composição bromatológica. In: REUNIÃO ANUAL DA SOCIEDADE BRASILEIRA DE ZOOTECNIA, 40., 2003, Santa Maria. Anais... Santa Maria: Sociedade Brasileira de Zootecnia, 2003. (CD-ROM).

CORREAA, C.E.S.; PEREIRA, M.N.; OLIVEIRA, S.G. et al. Performance of Holstein cows fed sugarcane or corn silages of different grain textures. Scientia Agrícola, v.60, p.621-629, 2003.

COSTA, M.G.; CAMPOS, J.M.S.; FILHO, S.C. et al. Desempenho produtivo de vacas leiteiras alimentadas com diferentes proporções de cana-de-açúcar e concentrado ou silagem de milho na dieta. Revista Brasileira de Zootecnia, v.34, p.2437-2445, 2005.

DRIEHUIS, F.; OUDE ELFERINK, S.J.W.H.; Van WIKSELAAR, P.G. Fermentation characteristics and aerobic stability of grass silage inoculated with Lactobacillus buchneri with or without homofermentative lactic acid bacteria. Grass and Forage Science, v.56, p.330-343, 2001.

DUBOIS, M.; GILLES, K.A.; HAMILTON, J.K. et al. Colorimetric method for determination of sugars and related substances. Analytical Chemistry, v.28, p.350, 1956.

FRANDSON, R.D.; WILKE, W.L.; FAILS, A.D. Anatomy and physiology of farm animals. 6.ed. Philadelphia: Koonan, 2003. 454p.

JUNQUEIRA, M.C. Aditivos químicos e inoculantes microbianos em silagens de cana-de-açúcar: perdas na conservação, estabilidade aeróbia e o desempenho de animais. Piracicaba: Escola Superior de Agricultura "Luiz de Queiroz”, 98p. Dissertação (Mestrado em Ciência Animal e Pastagens) - Escola Superior de Agricultura "Luiz de Queiroz”, 2006.

KUNG JR., L.; STANLEY, R.W. Effect of stage of maturity on the nutritive value of whole-plant sugarcane preserved as silage. Journal of Animal Science, v.54, p.689-696, 1982.

KUNG JR., L. Preparation of silage water extracts for chemical analyses. Standard operating procedure - 001 2.03.96. Worrilow: University of Delaware - Ruminant Nutrition Laboratory, 1996. 309p.

KUNG JR., L. Microbial and chemical additives for silage - effects on fermentation and animal response. In: WORKSHOP SOBRE MILHO PARA SILAGEM, 2000, Piracicaba. Anais... Piracicaba: Fundação de Estudos Agrários Luiz de Queiroz, 2000. v.2, p.53.

LUCCI, C.S.; VALVASORI, E.; LOPES. R. et al. Cana-de-açúcar (Saccharum officinarum) in natura ou ensilada, adicionadas ou não de uréia, em dietas para ruminantes. Digestibilidade aparente. Boletim da Indústria Animal, v.60, p.47-53, 2003.

MAGALHÃES, A.L.R.; CAMPOS, J.M.S.; VALADARES FILHO, S.C. et al. Cana-de-açúcar em substituição à silagem de milho em dietas para vacas em lactação: desempenho e viabilidade econômica. Revista Brasileira de Zootecnia, v.33, p.12921302, 2004.

MENDONÇA, S.S.; CAMPOS, J.M.S.; VALADARES FILHO, S.C. et al. Comportamento ingestivo de vacas leiteiras alimentadas com dietas ã base de cana-de-açúcar ou silagem de milho. Revista Brasileira de Zootecnia, v.33, p.723-728, 2004.

NATIONAL RESEARCH COUNCIL - NRC. Nutrient requirements of dairy cattle. 7.ed. Washington, D.C.: National Academy Press, 2001. 381p.

NISHIRO, N.; YOSHIDA, M.; SHIOTA, H. et al. Accumulation of 1,2 -propanediol and enhancement of aerobic stability in whole maize silage inoculated with Lactobacillus buchneri. Journal of Applied Microbiology, v.94, p.800-807, 2003.

NUSSIO, L.G.; CAMPOS, F.P.; DIAS, F.N. Importância da qualidade da porção vegetativa no valor alimentício da silagem de milho. In: SIMPÓSIO SOBRE PRODUÇÃO E UTILIZAÇÃO DE
FORRAGENS CONSERVADAS, 2001, Maringá. Anais.. Maringá: Universidade Estadual de Maringá, 2001. p.127-145. NUSSIO, L.G.; SCHMIDT, P. Silagens de cana-de-açúcar para bovinos leiteiros: aspectos agronômicos e nutricionais. In: VISÃO TÉCNICA E ECONÔMICA DA PRODUÇÃO LEITEIRA, 2005, Piracicaba. Anais... Piracicaba: Fundação de Estudos Agrários Luiz de Queiroz, 2005. p.193-218.

OLIVEIRA, R.L.; BARBOSA, M.A.A.F.; CUNHA, M.A.D. et al. Avaliação da silagem de milho em função do tempo de abertura e da inoculação enzimático-microbiana. In: REUNIÃO ANUAL DA SOCIEDADE BRASILEIRA DE ZOOTECNIA, 40., 2003 , Santa Maria. Anais... Santa Maria: Universidade Federal de Santa Maria, 2003. (CD-ROM).

PEDROSO, A.F. Aditivos químicos e microbianos como inibidores da produção de etanol em silagens de cana de açúcar (Saccharum officinarum L.). Piracicaba: Escola Superior de Agricultura "Luiz de Queiroz", 2003. 120p. Tese (Doutorado em Agronomia) - Escola Superior de Agricultura "Luiz de Queiroz", 2003.

PEDROSO, A.F.; NUSSIO, L.G.; BARIONI JR., W. et al. Desempenho de novilhas holandesas alimentadas com silagens de cana-de-açúcar tratada com uréia, benzoato de sódio ou Lactobacillus buchneri. Revista Brasileira de Zootecnia, v.35, p.649-654, 2006.

PIRES, A.V. Efeito da inclusão de fontes de amido e silagem de milho em dietas à base de cana-de-açúcar na digestibilidade de nutrientes e na produção de leite de vacas holandesas. Piracicaba: Escola Superior de Agricultura “Luiz de Queiroz”, 120p. Tese (Livre Docência) - Escola Superior de Agricultura "Luiz de Queiroz”, 1999.

PRYCE, J.D. A modification of Barker-Summerson method for the determination of lactic acid. Analyst, v.94, p.1151-1152, 1969.

RANJIT, N.K.; KUNG JR., L. The effect of Lactobacillus buchneri, Lactobacillus plantarum, or a chemical preservative on the fermentation and aerobic stability of corn silage. Journal of Dairy Science, v.83, p.526-535, 2000.

ROSA, J.R.P.; SILVA, J.H.S.; RESTLE, J. et al. Avaliação do comportamento agronômico da planta e valor nutritivo da silagem de diferentes híbridos de milho (Zea mays, L.). Revista Brasileira de Zootecnia, v.33, p.302-312, 2004.

ROTH, M.T.P.; REIS, R.A.; BERNARDES, T.F. et al. Valor nutritivo das plantas e das silagens de híbridos de milho (Zea mays). In: REUNIÃO ANUAL DA SOCIEDADE BRASILEIRA DE ZOOTECNIA, 41., 2004, Campo Grande. Anais... Campo Grande: Sociedade Brasileira de Zootecnia, 2004. (CD-ROM).

STATISTICAL ANALYSIS SYSTEM - SAS. SAS user's guide: statistics. Cary: 1999. 965p.

SILVA, D.J. Análise de alimentos (métodos químicos e biológicos) Viçosa, MG: Universidade Federal de Viçosa, 1981. 166p.

SIQUEIRA, G.R.; SCHOCKEN-ITURRINO, R.P.; BERNARDES, T.F. et al. Interações entr inoculantes microbianos e aditivos químicos na fermentação e na estabilidade aeróbia de silagens de cana-de-açúcar (Saccharum officinarum 1.). In: REUNIÃO ANUAL DA SOCIEDADE BRASILEIRA DE ZOOTECNIA, 41. 2004, Campo Grande. Anais... Campo Grande: Sociedade Brasileira de Zootecnia, 2004. (CD-ROM).

TOLEDO FILHO, S.G.; SCHIMIDT, P.; NUSSIO, L.G. et al. Estabilidade aeróbia de rações contendo silagens de cana-deaçúcar inoculadas com Lactobacillus buchneri 40788 e de ingredientes concentrados. In: REUNIÃO ANUAL DA SOCIEDADE BRASILEIRA DE ZOOTECNIA, 41., 2004, Campo Grande. Anais... Campo Grande: Sociedade Brasileira de Zootecnia, 2004. (CD-ROM). 